\title{
PRANTSUSE MODAALVERBI DEVOIR TEMPORAALSE KASUTUSE TÕLKIMISEST EESTI KEELDE
}

\author{
Marri Amon \\ Tartu Ülikool
}

Kokkuvõte. Artiklis vaadeldakse prantsuse keeles grammatiseerunud konstruktsiooni (modaalverb devoir imparfait ajavormis + põhiverbi infinitiiv, enamasti koos ajamäärusega) tõlkimise võimalusi eesti keelde, kus võrreldav modaalverbi kasutav konstruktsioon puudub, ehkki vastaval modaalverbil pidama on mõned postmodaalsed kasutused. Analüüsimiseks on valitud Eesti-Prantsuse Leksikograafiaühingu paralleelkorpusest näiteid ilukirjanduslike ja mitteilukirjanduslike tekstide tõlgetest prantsuse keelest eesti keelde. Prantsuse keeles on seda konstruktsiooni nimetatud "ajaloolase" mineviku aleetiliseks tulevikuks (Kronning 1996): seda kirjeldatakse kui fataalset või paratamatut tulevikku, millele viidatakse mingil hetkel mineviku jutustuses hiljem saadud teadmise valguses. Analüüsile tuginedes võib nentida, et tõlge pelgalt indikatiivi verbivormi abil on küll aktsepteeritav (kuivõrd ajamäärus kui tõlgendamise keskne element tõlkimisel üldiselt probleeme ei valmista), kuid leidub ka muid vahendeid, millega paremini edasi anda algse konstruktsiooni fataalset iseloomu. Mõnikord õnnestub tõlkijatel pakkuda välja alternatiivseid lahendusi.

Märksõnad: modaalverb devoir, postmodaalne, temporaalne kasutus, tõlge, eesti keel, prantsuse keel

DOI: http://dx.doi.org/10.12697/jeful.2016.7.2.01

\section{Sissejuhatus}

Käesolevas artiklis vaadeldakse prantsuse modaalverbi devoir tõlkimist eesti keelde juhtudel, mil prantsuse keeles on tegemist modaalverbi temporaalse kasutusega, mida üldiselt käsitletakse kui modaalverbi postmodaalset ehk mitte-episteemilist kasutust. Näited on kogutud kakskeelsest Eesti-Prantsuse Leksikograafiaühingu paralleelkorpusest, millest on otsingusse valitud prantsuse keelest eesti keelde tõlgitud ilukirjanduslikud ja mitteilukirjanduslikud tekstid (kokku 5,08 miljonit sõnet). Analüüsitud korpuses on 45 näidet koos tõlgetega. Pärast esmast sisuanalüüsi lülitati korpusesse esimesed sellele kasutusele vastavad näited. Temporaalne kasutus ei ole kindlasti verbi devoir keskseid 
kasutusi, kuid samas on vaadeldav tarind siiski produktiivne ja alati üheselt mõistetav. Analüüs on kvalitatiivne. Esmalt antakse lühike ülevaade vaatlusaluse devoir-tarindi käsitlustest, seejärel vaadeldakse lühidalt vastava eesti modaalverbi pidama kasutust modaalverbide grammatiseerumisprotsessi taustal. Eesti keeles ei ole vastava modaalverbi puhul välja kujunenud sama tüüpi temporaalset kasutust ning tõlkijad peavad lause mõtet teiste vahenditega edasi andma: et prantsuse keeles esineb lauses tihti ka ajamäärsõna, on selle tõlkimisega üldiselt võimalik originaali rõhuasetust väljendada. Üksikud näited, mis prantsuse keeles ajamäärust ei sisalda, kasutavad teistsuguseid vahendeid, mille eesmärgiks on kirjeldatud tegevus teatud moel siiski piiritleda. Nendes lausetes viidatakse verbifraasi abil kas pikemalt kestnud protsessile või kirjeldatakse mingit otsustava tähtsusega sündmust, mille tagajärjed on tuntavad pikemat aega. Tõlkimise seisukohast on huvipakkuv eeskätt see, et originaali modaalverb on osa spetsiifilisest konstruktsioonist ning selle tõlkimine modaalverbi abil ei ole eesti keelele omane. Seega on tähtis, et tõlkija vaatleks sellist lauset kui tervikut ning tunneks selle kasutuse ära. Artiklis uuritaksegi seda, millistes tingimustes tõlkijal enim raskusi võib tekkida, mismoodi tõlkijad on püüdnud neid lahendada ja kas on võimalik välja pakkuda ka üldisemat tõlkestrateegiat.

\section{Modaalverbide temporaalne kasutus}

Hans Kronningi järgi on tegemist modaalverbi mitte-episteemilise kasutusega ehk teisisõnu ei väljenda modaalverb tõenäosust, vaid eelkõige vältimatut paratamatust. Niisuguste kasutuste kirjeldamiseks, kus esiplaanil on paratamatuse mõiste, kasutab Kronning loogikast pärit terminit aleetiline (Kronning 1996, 2001). Sellise lausungi puhul ei ole näiteks võimalik kasutada episteemilise modaalsuse markereid, nagu "tõenäoliselt" või "arvatavasti". Erinevalt episteemilisest modaalsusest on aleetilist modaalsust võimalik hinnata tõe/vale skaalal. Johan van der Auwera ja Vladimir Plungian (1998) klassifitseerivad niisugused juhtumid postmodaalse kasutuse alla, ehkki temporaalseid kasutusi nad eraldi ei käsitle.

Temporaalse kasutuse puhul peetakse prantsuse keeles silmas põhiliselt tuleviku väljendamist modaalverbi ja sellel järgneva põhitegusõna infinitiivi abil. Modaalverb ise on minevikus (pr imparfait), mis tähendab seda, et tegemist on n-ö mineviku tulevikuga. Imparfait on prantsuse keele verbiparadigmas aeg, mida kasutatakse kirjelduste, 
tausttegevuste ja kestva tegevuse kirjeldamiseks. Seda saab kombineerida nii oleviku, lihtmineviku (pr passé composé) kui ka kirjaliku jutustuse mineviku (pr passé simple) ajavormiga. Kõige tüüpilisematel juhtudel esineb näites kirjeldus minevikus (pr passé simple või passé composé), mille juures tuuakse esile mingi selle mineviku suhtes edaspidi toimunud sündmus või hilisemal ajahetkel tehtud järeldus, kuid kohustusliku aegade ühildumise tõttu prantsuse keeles on modaalverb imperfekti, mitte morfoloogilise tuleviku vormis. Ent esineb ka näiteid, kus peamine ajavorm on olevik, kuid modaalverb on siiski imperfekti vormis. Sellisel juhul on tegemist näiteks objektiivse kirjeldusega, mis vormistatakse olevikus, ent modaalverbiga tuuakse sisse mõni tähelepanek, mis paigutub kõneleja olukorra kogemise hetke suhtes tulevikku.

Prantsuse keeles on Hans Kronning seda kasutust määratlenud kui "ajaloolase" mineviku aleetilist tulevikku (1996: 116); Hans NilssonEhle nimetab seda objektiivseks mineviku tulevikuks (1943-1944, 1.28, 18) ning Bernard Pottier assertiivseks prospektiiviks (1976: 40).

Modaalverbi devoir kasutuse eripäraks on siin see, et räägitakse tulevikus toimuvast sündmusest, lähtuvalt kahest referentsipunktist $\mathrm{r} 1$ ja r2. Kui võtta kõnelemise hetkeks t0, siis vaadeldakse tegevust prospektiivselt kahest perspektiivist: esiteks lähtudes referentsipunktist r1 (millele viitab modaalverb devoir imperfekti ajavormis ning mis on varasem tegevusest ning kõnelemise hetkest t0) ja teiseks retrospektiivselt niiöelda ajaloolaste referentsipunktist $r 2$, mis langeb kokku kõnelemise hetkega t0. Sageli on niisugustes lausungites ka ajamäärsõna, mis viitab asjaolule, et tegevus toimub (mineviku) tulevikus. Seda on pidanud kohustuslikuks näiteks Paul Imbs (1960: 70), ent näited Kronningi uurimuses (1996: 116-117) osutavad, et ajamäärsõna ei ole selle tõlgenduse puhul siiski hädavajalik.

Modaalverbe seotakse ka üldisemalt tuleviku väljendamisega, näiteks prantsuse keeles on modaalverbi devoir käsitletud episteemilises kasutuses tõenäolise tuleviku väljendajana, kuivõrd kohustuse väljendamine sisaldab tihti ka ideed, et mingi tegevus tuleb tulevikus ära teha. Ent nagu ülal nägime, ei kuulu niisugused kasutused alati episteemilise modaalsuse alla, mida Kronning käsitleb kui objektiivset minevikku tulevikus või n-ö paratamatut, fataalset tulevikku (Kronning 1996, 2001).
(1) Juhtus see, mis juhtuma pidi.
Ce qui devait arriver est arrivé. 
Modaalverbi devoir on sellistel juhtudel prantsuskeelsetes uurimustes nimetatud ka tuleviku abitegusõnaks (auxiliaire du futur). Traditsiooniliselt on tegusõna devoir nendel puhkudel liigitatud episteemilise kasutuse alla (Dendale 1999), kuid lähtudes ideest, et episteemilisel ja mitteepisteemilisel tõlgendusel on suur semantiline ühisosa, pakuvad Carl Vetters ja Cécile Barbet (2006: 205) välja seda tüüpi tuleviku kasutuse klassifikatsiooni, milles on kaks rühma: esiteks, konventsionaalne ehk kokkuleppeline tulevik, mis on ühtlasi ka mitte-aleetiline kasutus ning seotud mitte-episteemilise/radikaalse tähendusega (kohustus või kokkulepe midagi teha), ning teiseks grammatiseeruv n-ö fataalne (paratamatu) tulevik, mis rajaneb verbi devoir aleetilisel tähendusel (absoluutne vajadus). Esimese kohta toovad nad mitmesuguseid näiteid, kus modaalverb viitab tulevikule ning esineb erinevates ajavormides:

(2) A l'origine, seul le major Novak devait participer à l'opération mais au dernier moment Mac Bodin vint se joindre à lui, perpétuant cette notion des jumeaux de l'espace qui semble s'instaurer.

Esialgu pidi operatsioonis osalema major Novak üksi, ent viimasel hetkel liitus temaga Mac Bodin, põlistades sellega kosmose kaksikute mõistet, mis tundub valdavaks saavat. [Artikli autori tõlge.]

Teise rühma näited eristuvad selgelt selle poolest, et lauses esineb etteruttav tuleviku väljendamine mingi minevikusündmuse jutustamisel.

Alljärgnevas keskendumegi teise rühma näidetele, mis väljendavad n-ö paratamatu või fataalse tuleviku tähendust.

\section{Tuleviku väljendamine ja modaalverbide grammatiseerumine eesti keeles}

Eesti keeles väljendab tulevikku enamasti oleviku ajavorm, millega kombineeritakse leksikaalseid vahendeid (ajamäärus), lisaks on levinud ka verbikonstruktsioonid saama + supiini illatiiv ning hakkama + supiini illatiiv koos ajamäärusega (Erelt 2013: 100-101).

Modaalverbil pidama (prantsuse verbi devoir esmane, vajadust, kohustust väljendav vaste) on agendikeskse vajaduse väljendamisel ka tulevikku hõlmav tähendus, näiteks Ma pean selle ära tegema. Vanemas eesti kirjakeeles on see verb olnudki esmajoones tuleviku väljendaja (Habicht 2001: 166) ning kui esimestes Uue Testamendi tõlgetes kasutati 17. sajandi keskel ohtrate tulevikuvormide vastetena verbi saama, siis Hornungi tõlkeversioonis (Müncheni käsikiri aastast 1694) hõivab selle koha tegusõna pidama, kusjuures see verb esineb lisaks tuleviku 
tähendusele ka mitmetes mittetulevikulistes tähendustes (Kilgi 2010: 173).

Modaalverbi grammatiseerumisprotsessi, kus agendikeskne modaalverb muutub tulevikus kavatsust väljendavaks verbiks ja sealt edasi tuleviku abitegusõnaks, on kirjeldanud Bybee jt (1991). Eesti keeles on Helle Metslang (1994: 543-545, 603-607) näidanud verbidega saama ja hakkama seotud tarindite arenguteed tuleviku abitegusõnaks kujunemisel. Mati Erelt (2001: 12-15) toob mitmeid näiteid pidama kasutuste kohta, mida ei saa küll veel käsitada päris tuleviku abitegusõnana, kuid mille puhul on toimunud tähendusnihkeid, näiteks tulevikku suunatud kavatsusest on saanud teatud tingimustes pidama-verbi põhitähendus:

(3) Rahvusvaheline filmikriitikute žürii tegi oma otsuse juba laupäeva lõunaks, sest žürii president pidi Pariisi oma naise sünnipäevale lendama.

Üks üsna levinud tähendusi on avertiivne ehk peaaegu toimunud sündmus, mis siiski ei toimunud (Kuteva 1999 järgi), kusjuures modaalverb pidama esineb selles kasutuses ainult imperfektis:

\section{(4) Jüri pidi üllatusest pikali kukkuma.}

Teiseks esineb pidama kvotatiivse evidentsiaalsuse väljendajana, samuti peamiselt imperfekti ajavormis:

\footnotetext{
"Nad jagasid linnas väikeseid lipikuid ka inimestele ja ma kuulsin, et praegugi pidi neid mitmes kohas maas vedelema," ütles abiprefekt.
}

\section{Korpuse näidete analüüs}

Alljärgnevas vaadeldakse võrdleva analüüsi käigus tõlkenäiteid, keskendudes probleemsematele, eesmärgiga tuvastada tegureid, mis tõlkimisel lõpptulemust mõjutavad. Artikli algse korpuse moodustavad 45 näidet eesti-prantsuse paralleelkorpuse tekstidest: otsingusse hõlmati tõlked prantsuse keelest eesti keelde ning tekstitüüpidest ilukirjanduslikud ja mitteilukirjanduslikud tekstid. Näite keskne lause on see, milles esineb originaalis tegusõna devoir imperfekti vormis, ja lause ning sellele eelneva ja järgneva teksti analüüs osutab, et tegemist on modaalverbi devoir temporaalse kasutusega. Verbivormidest on analüüsi valitud (kõige sagedamini esinevatena) ainsuse esimene (17 näidet) ja kolmas pööre (28 näidet). 
Tegusõnad, mis on seotud modaalverbiga, on enamasti abstraktsed, viidates tihti teadvustamisega seotud protsessidele. Tüüpiliselt esinevad verbid, mis osutavad ühekordsele tegevusele, näiteks apprendre 'teada saama', reconnaître 'ära tundma', identifier 'tuvastama', perdre de vue 'silmist kaotama', se rendre compte 'taipama'. Konkreetsemaid tegevusi väljendavad verbid esinevad enam näidetes, kus modaalverb on ainsuse kolmandas pöördes, näiteks partir 'ära minema', revenir 'tagasi tulema', rire 'naerma', dire 'ütlema'.

Enamik modaalverbi sisaldavaid lauseid räägib mingist sündmusest või protsessist, mille mõju jääb minevikku, kas lõpeb seal või ei ole tegevuse lõppu selgelt väljendatud. Erandlikult võib kirjeldatud protsess olla ka selgelt seostatud kõnehetkega t0:

(6) Mais la conversation de Dharamsala m'est aussitôt revenue à l'esprit et un peu vexé, je l'avoue, qu'un autre traitement que celui que je maîtrisais ait été plus utile - je décidai de m'informer de ce qu'on savait de cette étrange pratique. Ce que je devais apprendre me laisse encore confondu par l'étendue de ses conséquences sur la nature du corps et du cerveau. Kuid mulle tuli otsekohe meelde jutuajamine Dharamsalas ja - tunnistan, pisut pahasena selle üle, et üks teine raviviis kui see, mida mina oskan, oli kasulikumaks osutunud - otsustasin järele uurida, mida selle imeliku tegevuse kohta teada on. See, mida ma pidin teada saama, tekitab minus veel praegugi segadust tagajärgede ulatuslikkuse tõttu, mida see kutsub esile nii keha kui aju olemuses.

Selles näites on ühena vähestest (kokku oli neid näiteid kolm) tõlkija ka eesti keeles säilitanud modaalverbi, mis võib olla tingitud ekslikust analüüsist.

Modaalverbi säilitamine tõlkes tekitab üldiselt eestikeelses lauses ebakõla, kuivõrd pidama esmane kohustuse tähendus on tugevalt esiplaanil ning ei episteemilise ega kvotatiivse evidentsiaalsuse väljendamine ole sellistes lausetes mõeldav tõlgendusvõimalus. Liiatigi ei ole viimase puhul eesti keeles kasutusel mitte ainsuse esimene, vaid ainult kolmas pööre.

Enamasti aitab ajamäärus oma tiheda seotuse tõttu verbifraasiga tõlkijal modaalverbi esmatähendust n-ö välja lülitada, kuid mõnel juhul jätab ajamääruse paiknemine originaaltekstis avatuks rohkem tõlgendusvõimalusi: 
(7) Mais à présent il était porté par cet amour. Il ne s'était plus arrêté, parcourant encore plus de cent kilomètres dans la neige avant d'atteindre un village. Plus tard, il devait dire: Ce que j'ai fait, aucune bête au monde ne l'aurait fait. Lorsque sa survie n'avait plus été une motivation suffisante, c'est sa conscience des autres, son amour qui lui avaient donné la force de continuer.

Aga nüüd kandis teda see armastus. Ta ei peatunudki enam, käis läbi lume maha üle saja kilomeetri, enne kui ühe külani välja jõudis. Hiljem pidi ta ütlema: Seda, mida mina tegin, poleks maailmas mitte ükski loom teinud. Kui ellujäämine ei olnud enam küllaldane motivatsioon, siis oli selleks ta südamevalu teiste pärast, armastus oli talle andnud jõudu edasi minna.

Näites (7) on ajamäärus lause alguses ja mõjutab seega kogu lauset ning tõlkija jaoks ei ole niisugune konstruktsioon arvatavasti niisama selgelt tõlgendatav kui laused, kus määrus asub kas modaalverbi ja infinitiivi vahel või nende järel. Eestikeelset lauset on võimalik mõista nii, et toimunud sündmused sundisid inimest teatud järeldust tegema, s.t tegu on siiski agendikeskse tõlgendusega, samal ajal kui prantsuse keeles on rohkem tunda prospektiivset tähendust ehk jutustuse sees on ajalise liigenduse abil viidatud hiljem toimunud sündmusele, kusjuures sunni või kohustuse tähendus ei ole siin tuntav.

Nagu öeldud, esineb peaaegu kõigis prantsuskeelsetes lausetes ajamäärus, mis viitab tulevikus toimuvale sündmusele. Enamasti on tõlkijad seda üsna täpselt edasi andnud, kuna tegu on selle konstruktsiooni keskse elemendiga, mis annab modaalverbi puudumisel soovitud tõlgenduse. Näiteks plus tard - 'hiljem', jamais - 'enam kunagi', par la suite - 'seejärel', seulement des années plus tard - 'alles mitu aastat hiljem', bientôt - 'varsti', vite, prochainement - 'peagi', rapidement 'kiiresti', toute sa vie - 'kogu eluks'. Suurem osa määrsõnu viitab ootuspäraselt tulevikusündmusele, mis võib olla kas ühekordne, kestev või määratlemata kestusega.

(8) Elle n'eut pas le cœur de me laisser chez M. Vedel; et c'est ainsi que commença pour moi cette vie irrégulière et désencadrée, cette éducation rompue à laquelle je ne devais que trop prendre goût.

Tal polnud südant mind Vedeli juurde jätta ning sellega algas minu jaoks see korrapäratu ja rahutu elu, see katkendlik haridustee, mis oli mulle liigagi meelepärane.

Selles näites on verbiga devoir kasutatud verbiühendit prendre goût, mis koos verbiga devoir imperfekti vormis viitab pikemale protsessile 
ning mis on eesti keelde tõlgitud staatilise verbiühendiga meelepärane olema. Pikemale protsessile viitavad siin loomulikult ka muud vahendid, nagu verb algama ning haridustee, kuid eesti keeles võib siin kaaluda ka verbi saama mittemodaalset kasutust: "mis mulle liigagi meelepäraseks sai".

Korpuses esineb kolm näidet, mis ei sisalda devoir-tarindi juures ainult kitsas mõttes ajamäärust, vaid määrsõna või muid konstruktsioone, mis osutavad mingi sündmuse kaalukale mõjule või lõplikule seisundimuutusele teatud minevikulisel ajahetkel, millele jutustuses tagasi vaadatakse. Siin esitatud näidetes (9) ja (10) on selgelt näha, et nendes lausetes on kesksel kohal protsessi kirjeldus kas aspekti vaatenurgast (pr progressivement 'järk-järgult'), selle lõplik mõju või tagajärjed (pr définitivement 'sügavalt', un rôle décisif dans sa vie 'otsustavat rolli tema elus', par la suite 'hiljem'), millega seostatakse korduv tegevus.

(9) Michel en prenait progressivement conscience, et devait en rester définitivement marqué.

Michel teadvustas neid endale järk-järgult ning need mõjutasid teda sügavalt.

(10) Cette conversation devait pourtant jouer un rôle décisif dans sa vie, et par la suite il se la remémora de nombreuses fois, sans d'ailleurs jamais parvenir à en ressentir une réelle émotion.

Ometi mängis see jutuajamine tema elus otsustavat rolli ning hiljem meenutas ta seda korduvalt, suutmata muuseas tunda midagi erilist.

Prantsuse keele analüüsides on vaatlusalust konstruktsiooni ehk verbi devoir temporaalset kasutust käsitletud osana paratamatust või fataalsust väljendavatest konstruktsioonidest (näiteks koos määrsõnaga fatalement). Kogu paralleelkorpuses on ainult üks näide, mis sisaldab määrsõna fatalement koos modaalverbiga devoir, kuid siin on selgelt tegemist deontilise modaalsusega, kus devoir põhitähendus on säilinud ning prospektiivset tähendust ei saa tuvastada:

(11) Entre l'homme qui prendrait leur tête, et eux, qui le talonneraient sans répit, sans défaillance, sans perte d'attention, une lutte fatalement devait s'engager?

Kas ei tundu, et nende etteotsa asunud mehe ja nende endi vahel, kes nad talle väsimatult, vääramatult ja järjekindlalt kandadele astuvad, peab paratamatult puhkema võitlus? 
Eestikeelses tõlkes on küll modaalverbi tunduma eituse abil lisatud lausesse episteemiline hinnang, mida võib seostada originaalis esinevate konditsionaali verbivormidega prendrait ja talonneraient, kuid see on kaasa toonud väikese tähendusnihke: originaalis on tõenäosusskaalal hinnatud üht sündmust, kuid tõlkes on see esitatud juba kindlalt toimunud sündmusena. Üks võimalus oleks siin tõepoolest vormistada tõlkes lause alguse kas-küsimus, kuid mitte eitavas vormis, näiteks: Kas on arvata, et nende etteotsa asuva mehe ja nende endi vahel [---] peab paratamatult puhkema võitlus?

Verbikonstruktsiooni asemel saab tõlgetes väga hästi kasutada ka teistsuguseid, näiteks leksikaalseid vahendeid:

(12) Il y avait primitivement, contre l'usine, une maison rectangulaire, petite, modeste, insignifiante au point de n'avoir laissé aucune trace en mon esprit, que mon oncle fit abattre, pour bâtir, sinon à la place, du moins un peu plus loin, bien en face de ce qui devait devenir le jardin, une habitation prétentieuse et cossue qui tenait du chalet de bains de mer et de la maison normande.

Algselt oli vabriku vastas väike tagasihoidlik karbikujuline ja nii ilmetu maja, et ta pole mu mällu mingit jälge jätnud; onu laskis selle maha lammutada, et ehitada samale kohale või pisut eemale, otse tulevase aia vastu uhke ja pompöösne elumaja, milles oli nii supelmaja kui ka Normandia talumaja jooni.

Selle lause tõlkimisel on keeruline säilitada asesõnalist korrelaati (ce), mistõttu tõlkija on kogu devoir-tarindi asendanud omadussõnaga tulevane. Teine võimalus oleks leida korrelaadile nimisõnaline vaste, näiteks otse maatüki vastu, millest hiljem pidi aed saama. Siinkohal võib märkida, et modaalverb pidama tundub eesti keeles sellisesse lausesse päris hästi sobivat, kuna koos modaalverbiga devenir väljendab see kavatsuslikkust. Lause väljendab siiski tulevikus toimumist selgemini, kui lisada ajamäärus hiljem vms.

Originaali ja tõlkelauseid võrreldes võib veel tekkida küsimus, kas infinitiivse devoir-tarindi tõlkimisel tavalise indikatiivi vormi abil ei lähe siiski mõned nüansid kaduma, kuna ei saa päris kindlalt väita, et verbi devoir esmane tähendus ei ole prantsuse keeles enam üldse tajutav: koos ajamäärusega, mis paigutab sündmuse ajaliselt mineviku suhtes tulevikku, ning koos hilisema teadmisega selle toimumise kohta, jääb siiski mulje, et kirjeldatud sündmus pidi juhtuma. Mõnes tõlkes on ka näha, et tõlkija on sellest juhindunud ja püüdnud seda nüanssi teiste vahenditega edasi anda: 
(13) Je ne devais jamais revoir Tisserand; il se tua en voiture cette nuit-là, au cours de son voyage de retour vers Paris.

Läks nii, et ma ei näinud Tisserand'i enam kunagi; ta sai samal ööl teel Pariisi autoõnnetuses surma.

Selle lause esimeseks elemendiks oleks võinud ka olla tegevuse subjekt $m a$, nagu on originaalis je, kuid lisades algusesse Läks nii, annab tõlkija paremini edasi sündmuse mitmes mõttes fataalset olemust.

Et uuritav korpus ei ole väga mahukas, on keeruline hinnata modaalverbi devoir temporaalse kasutuse esinemistingimusi või -sagedust prantsuse keeles. Korpuse näidete hulgast tõusid esile Claude LéviStraussi "Nukra troopika" tsitaadid ning tundub, et see autor kasutab oma tekstis üsna sageli kommentaare või tähelepanekuid, millega ta etteruttavalt mainib teatavate sündmustega seotult ka olukorra suhtes hiljem omandatud teadmisi või järgnenud sündmusi. Seega on kogu teost arvestades tegemist võttega, mis aitab jutustust paremini tervikuks siduda.

(14) Je prévins l'intéressé qui disparut aussitôt; je ne devais le revoir que plusieurs mois plus tard, à mon retour dans la région.

Ma hoiatasin asjaosalist, kes selle peale kohe kadus; kohtasin teda uuesti alles mitme kuu pärast, kui taas sellesse piirkonda tulin.

(15) Dès qu'on s'écarte du centre de Rio, qui fait alors très début de siècle, on tombe dans des rues tranquilles, de longues avenues plantées de palmiers, de manguiers et de palissandres taillés, où s'élèvent des villas désuètes dans des jardins. Je songe (comme je devais le faire plus tard dans les quartiers résidentiels de Calcutta) à Nice ou à Biarritz sous Napoléon III.

Niipea kui eemalduda Rio kesklinnast, mis meenutab väga sajandi algust, satutakse vaiksetele tänavatele, pikkadele puiesteedele, mille ääres kasvavad palmi- ja mangopuud ning pügatud palisandrid ja kus aedade keskel seisavad vanamoodsad villad. Mulle kangastub (nagu hiljem Calcutta elamukvartalites) Napoleon III aegne Nizza või Biarritz.

Viimases näites on tõlkija jätnud igati põhjendatult tõlkimata tähenduselt üsna tühja, ent prantsuse keeles stiililiselt ja grammatiliselt sobiva tarindi koos verbiga faire ('tegema'). 


\title{
5. Kokkuvõte
}

Korpuse analüüs aitas valgust heita eesti modaalverbi pidama postmodaalse kasutuse piiridele ja tõdeda, et tõlkimisel ei saa ka kõige lihtsamana näivate elementide puhul juhinduda sõnasõnalisest vastest, vaid tuleb analüüsida kogu tarindit ning laiemalt kogu lõiku, milles see konstruktsioon esineb.

Eesti keeles puudub grammatiseerunud konstruktsioon mineviku jutustuses vältimatu ehk etteruttavalt edaspidise teadmise valguses väljendatava tuleviku vormistamiseks, mis prantsuse keeles on üsna levinud modaalverbi devoir imperfektivormi kasutamisel koos põhiverbi infinitiiviga, millele enamasti lisandub ajamäärus.

Ehkki eesti modaalverbil pidama on mitmeid postmodaalseid kasutusi, ei saa seda tegusõna siiski käsitada kui tuleviku abitegusõna näiteks avertiivi ja kvotatiivse tähenduse puhul ei ole võimalik kasutada muid aegu peale imperfekti.

Tõlkijad on üldiselt temporaalset tähendust eesti keele vahenditega arusaadavalt edasi andnud, välja arvatud paaril juhul, kus on pakutud sõnasõnalist tõlget, kasutades modaalverbi pidama, mis tekitab lause mõistmisel ebakõla. On arusaadav, et juhtudel, mil see võimalik on, püüavad tõlkijad toime tulla enam-vähem sõnasõnalise tõlkega, sest suur osa tõlkijate pingutustest läheb leksikaalsete vastete leidmisele ning näiteks verbikonstruktsiooni asemel teistsuguse tarindi pakkumiseks on esmalt tarvis algsõnumit õigesti analüüsida ning on ka alust arvata, et suurem vabadus tõlkimisel tuleb koos rohkemate kogemustega. Samas tuleb tõdeda, et sellele tarindile iseloomulik fataalsuse nüanss, mis on prantsuse keeles tänu modaalverbi devoir esmasele tähendusele tajutav, jääb eesti keeles siiski vajaka (modaalverb pidama seda funktsiooni praegu ei täida), mistõttu tasub tõlkimisel ehk rohkem rõhku panna veidi vabamale sõnastusele, mis võimaldab pelgast indikatiivist kui n-ö minimaalsest tõlkevastest kaugemale minna ja lause kui terviku tähendust paremini edasi anda.

\author{
Aadress: \\ Marri Amon \\ Maailma keelte ja kultuuride kolledž \\ Tartu Ülikool \\ Lossi 3 \\ 51003 Tartu, Eesti \\ E-post:marri.amon@ut.ee
}




\section{Korpus}

Eesti-Prantsuse Leksikograafiaühingu Eesti-prantsuse paralleelkorpus / Corpus parallèle estonien-français, kättesaadav aadressil: <http://corpus.estfra.ee>. Vaadatud 03.05.2016.

\section{Kirjandus}

Bybee, Joan L., William Pagliuca and Revere D. Perkins (1991) "Back to the future", Approaches to grammaticalization II, 17-58. (Typological Studies in Language, 19: 2.) Amsterdam and Philadelphia: John Benjamins.

Dendale, Patrick (1999) “'Devoir' au conditionnel: valeur évidentio-modale et origine du conditionnel", Cahiers Chronos 8, 33-46.

Erelt, Mati (2001) "Some notes on the grammaticalization of the verb pidama". In Mati Erelt, ed. Estonian: Typological Studies V, 7-25. (Eesti keele õppetooli toimetised, 18.) Tartu: Tartu Ülikooli Kirjastus.

Erelt, Mati (2013) Eesti keele lauseõpetus. Sissejuhatus. Öeldis. (Tartu Ülikooli eesti keele osakonna preprindid, 4.) Tartu: Tartu Ülikool.

Habicht, Külli (2001) "Vanhan kirjaviron modaalirakenteista". In Tõnu Seilenthal, ed. Congressus Nonus Internationalis Fenno-Ugristarum 7.-13.8.2000. Pars IV. Dissertationes sectionum: Linguistica I, 268-276. Tartu.

Imbs, Paul (1960) L'emploi des temps verbaux en français moderne. Essai de grammaire descriptive. Paris: Klinksieck.

Kilgi, Annika (2010) Tõlkekeele dünaamika piibli esmaeestinduse käigus: verbi morfosüntaksi areng ja lõplik toimetamisfaas. Doktoritöö. Tallinna Ülikool. Tallinn: Tallinna Ülikooli Kirjastus.

Kronning, Hans (1996) Modalité, cognition et polysémie: sémantique du verbe modal “devoir". (Acta Universitatis Upsaliensis.) Uppsala and Stockholm: Almqvist \& Wiksell International.

Kronning, Hans (2001) "Pour une tripartition des emplois du modal devoir". Cahiers Chronos 8, 67-84.

Kuteva, Tania (1999) "TAM-auxiliation, and the avertive category in Northeast Europe". Grammaticalisation aréale et sémantique cognitive: les langues fenniques et sames, 27-41. (Oural-Ural 1.) Tallinn.

Metslang, Helle (1994) "Eesti ja soome - futuurumita keeled?" Keel ja Kirjandus 9, 534-547, 10, 603-616.

Nilsson-Ehle, Hans (1943-1944) “Le conditionnel 'futur du passé' et la périphrase devait + infinitif”. Studia Neophilologica 16, 50-88.

Pottier, Bernard (1976) "Sur la formulation des modalités en linguistique". Langages 10: $43,39-46$.

Van der Auwera, Johan and Vladimir Plungian (1998) "Modality's semantic map". Linguistic Typology 2, 79-124.

Vetters, Carl et Cécile Barbet (2006) "Les emplois temporels des verbes modaux en français: le cas de devoir". Cahiers de praxématique 47, 191-214. 


\begin{abstract}
Marri Amon: About translating temporal uses of the French modal verb devoir into Estonian. This paper aims to explore the possibilities of translating a grammaticalised construction (devoir in imparfait tense + Inf, generally along with a temporal adverb) from French into Estonian where such a construction does not exist, although the corresponding modal verb pidama has also some postmodal uses. In order to address this question, examples of literary and non-literary translations from Estonian-French parallel corpus are analysed. In French, this construction is considered as an alethic future of the "historian's" past (Kronning 1996), a fatal, inevitable future that emerges in some point of a past story in light of later acquired knowledge. The analysis demonstrates that although a translation by an indicative verb form is acceptable (translating the temporal adverb as the central element that guides the interpretation of the sentence is not problematic), other means are also available to express the fatal character of the original construction, and sometimes translators succeed in proposing an alternative translation.
\end{abstract}

Keywords: modal verb devoir, postmodal, temporal use, translation, Estonian, French 